\title{
Elephant seal foraging dives do indeed track prey distribution, but temperature influences the distribution of prey: Reply to Boersch-Supan et al. (2012)
}

\author{
Trevor McIntyre ${ }^{1, *}$, Isabelle J. Ansorge ${ }^{2}$, Horst Bornemann ${ }^{3}$, Joachim Plötz ${ }^{3}$, \\ Cheryl A. Tosh ${ }^{1}$, Marthán N. Bester ${ }^{1}$ \\ ${ }^{1}$ Mammal Research Institute, Department of Zoology and Entomology, University of Pretoria, Private Bag X20, Hatfield 0028, \\ South Africa \\ ${ }^{2}$ Department of Oceanography, Marine Research Institute, University of Cape Town, Rondebosch 7701, South Africa \\ ${ }^{3}$ Alfred Wegener Institute for Polar and Marine Research, Postfach 120161, 27515 Bremerhaven, Germany
}

\begin{abstract}
McIntyre et al. (2011a; Mar Ecol Prog Ser 441:257-272) illustrated a number of relationships between environmental variables and the dive behaviour of satellite-tracked southern elephant seals Mirounga leonina. One of these associations was that seals tended to increase their dive depths and spend less time at targeted dive depths when swimming in warmer waters. Boersch-Supan et al.'s (2012; Mar Ecol Prog Ser 461:293-298) comment on this study suggests that the link described between dive depths and in situ temperature is actually a link between dive depths and prey distribution. We do not dispute this assertion, having discussed this likelihood in McIntyre et al. (2011a). Boersch-Supan et al. (2012) further provide a number of criticisms, based partly on their observations of potential prey distributions within a comparatively small geographic area. We argue that their results are not directly comparable to those presented in McIntyre et al. (2011a) given the limited spatial overlap of the study areas and sparse, small-scale dataset presented. We further provide replies to technical comments by Boersch-Supan et al. (2012) pertaining to our data analyses.
\end{abstract}

KEY WORDS: Southern elephant seals · Foraging ecology · Climate change · Marion Island · Bio-logging

\section{Introduction}

We undertook a comprehensive statistical analysis, using time-depth profile data obtained from 149916 dives undertaken by southern elephant seals $M i$ rounga leonina to show that elephant seals of the Marion Island population alter their dive behaviour in waters of differing temperatures (McIntyre et al. 2011a). Various other factors were taken into account in this investigation and shown to also influence the dive depths and relative times spent at depth by our study population. Temperature-at-depth was one of the variables that consistently showed a positive relationship with dive depths (seals diving deeper in warmer waters) and a negative relationship with a time-at-depth index (seals spending less time during the bottom phases of dives in warmer waters). We concluded that this relationship was likely to be due to differences in prey distribution associated with different temperature regimes (and likely other oceano- 
graphic features) - suitable prey species tending to occur at deeper depths in warmer waters. This overall tendency led us to hypothesise that distribution shifts of potential prey species (either poleward and/or to deeper depths) associated with a warming ocean, will likely lead to the Marion Island elephant seal population incurring greater physiological costs associated with hunting for prey.

Boersch-Supan et al. (2012, this volume) argue that our analyses were unsuitable for detecting effects of climate change on the behaviour of elephant seals, based partly on their observations from a single cruise, presenting a snapshot of conditions within a limited area of the Southwest Indian Ocean, as well as some technical comments on the methods we followed. Here, we illustrate that the data reported by Boersch-Supan et al. (2012) are not informative in the context of our study, and we provide arguments in favour of our analyses and discussion in McIntyre et al. (2011a).

\section{Limited spatial overlap in study areas}

Boersch-Supan et al. (2012) report echogram and CTD (12 CTD casts in total) data collected along a single transect between $38^{\circ}$ and $\sim 41.5^{\circ} \mathrm{S}$ (no longitude data provided) at an unreported time of year. This transect crosses the Subantarctic Front and illustrates differences in the vertical structure of backscatter layers (indicative of biomass distribution) on either side of the front. However, the seals tracked in our sample spent very little time in the latitudinal area sampled by Boersch-Supan et al. (2012) — the median latitudinal location of the dive records presented in McIntyre et al. (2011a) is $47.6^{\circ} \mathrm{S}$ (range: $39.3^{\circ}$ to $69.8^{\circ} \mathrm{S}$ ). In fact, less than $1.5 \%$ of the dives analysed in our study fall within the latitudinal range reported on by Boersch-Supan et al. (2012). This lack of overlap with the area utilised by the seals from our study severely limits the usefulness of their echogram dataset in interpreting the behaviour displayed by the tracked seals and makes comparisons between the 2 datasets uninformative.

\section{Temperature, frontal zone positions, daily averages and seasonal effects}

Boersch-Supan et al. (2012) suggest that it would have been more appropriate to use in situ temperatures recorded at foraging depth, instead of the maximum temperature recorded below $100 \mathrm{~m}$ during a dive $\left(T_{\max } 100\right)$. For our assessment we required a parameter that would provide some information on the general water structure where the seals were diving. Since elephant seals display much variability in the depths that they dive to (McIntyre et al. 2011b, in press), it would not have been informative about the water structure to use the temperature recorded at foraging depth. Since we used $T_{\max } 100$ as an indication of the general water temperature structure, rather than an ocean warming indicator as stated by Boersch-Supan et al. (2012), our analyses remain valid. Furthermore, since the seals tracked in our study often crossed the Polar Front, the water structure did not always show a monotonic decline in temperature as depths increased beyond shallow temperature maxima, resulting in $T_{\max } 100$ values that were often recorded at depths between 200 and $800 \mathrm{~m}$ (Fig. 1). This also makes Boersch-Supan et al.'s (2012) comment regarding the definition of frontal locations based on temperature at $100 \mathrm{~m}$ irrelevant to our study, given that $T_{\max } 100$ is not the same as temperature at $100 \mathrm{~m}$ in our samples.

In the models used for the analyses of the data presented in McIntyre et al. (2011a), we incorporated a factor to explicitly quantify the effect of dive location in relation to frontal locations. In contrast to what Boersch-Supan et al. (2012) suggested, this factor was retained in 3 of the 4 models explaining dive depths recorded by the seals in our sample (daytime dive depths for males and females as well as nighttime dive depths for females). This result supports Boersch-Supan et al.'s (2012) observation that biomass distributions do indeed differ between frontal zones. However, Boersch-Supan et al. (2012) further suggest that the reason this factor was dropped from some of the final models in our study was likely due to a colinearity between the $T_{\max } 100$ values and the positions relative to frontal zones (based on their assumption that the $T_{\max } 100$ values were always recorded close to $100 \mathrm{~m}$ depth, and therefore were suggestive of frontal location). Instead, this factor was dropped from some of our models because most of the dives in our sample were recorded interfrontally, between the Subantarctic Front and the Antarctic Polar Front. This 'skew' in the data meant that the effect of frontal zone on the behaviour of tracked seals would have had to be comparatively large (compared to other environmental variables) to have substantial influence in the final models selected. The retention of frontal zone in the final models for dive depths suggests a comparatively strong influence of frontal zone on the dive depths displayed by the tracked seals. 


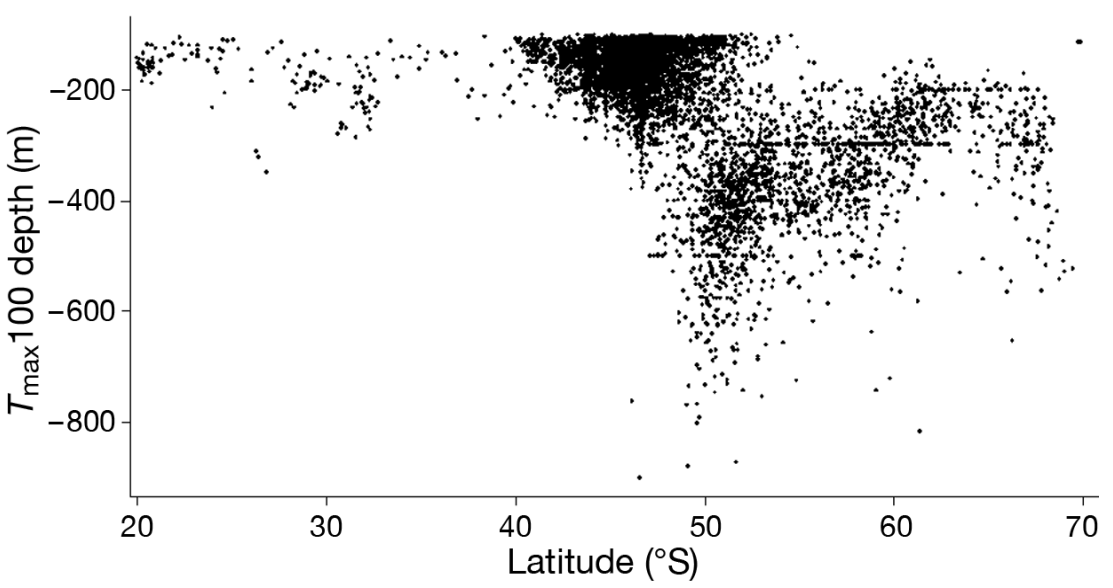

Fig. 1. Depths at which the maximum temperature recorded below $100 \mathrm{~m}$ ( $\left.T_{\max } 100\right)$ values were recorded at various latitudinal positions by McIntyre et al. (2011a)

As stated in McIntyre et al. (2011a), transmitted dive and temperature profiles do not necessarily correspond either temporally or spatially with one another due to the storage of information onboard the satellite-relay data loggers prior to transmission. For this reason we used daily averaged values to assist in the temporal aligning of behavioural parameters with environmental variables. Such analysis obviously results in extensive loss of detail within the dataset, which is not ideal. While we could potentially have used a finer temporal scale, this would likely not have substantially improved our results, particularly given the tendency of elephant seals to spend extended periods of time within restricted areas while foraging (e.g. Campagna et al. 2007, Tosh et al. 2009). These extended residence times at sea would have greatly reduced the loss of information.

Boersch-Supan et al. (2012) criticise the omission of season as a factor in our assessment of environmental influences on the dive behaviour of elephant seals; however, we included migration stage (post-breeding vs. post-moult, a proxy for time of year) in all models. Elephant seals mostly haul out onto land twice a year: once for the annual breeding season (austral spring), and once for the obligatory annual moult (austral summer) (Le Boeuf \& Laws 1994). This results in 2 'migration stages' identified within our sample that loosely correspond to overwintering (post-moult), and summer (post-breeding) migrations. While seasonality could perhaps have been included at a finer temporal scale, the overall influence of season (winter vs. summer) was taken into account through the incorporation of migration stage into all initial models.

\section{Effect sizes, time-at-depth and foraging success}

On average, Marion Island elephant seals dive deeper (and longer) than those from any other population, with adult males diving to daytime depths of $618.1 \pm 258.6 \mathrm{~m}( \pm \mathrm{SD})$, and adult females to $552.2 \pm 170.1 \mathrm{~m}$ (McIntyre et al. 2011b, in press). Boersch-Supan et al. (2012) question the biological relevance of the statistical relationships we described between temperature at depth and dive behavioural parameters. We agree that the effect sizes suggested by our models are comparatively small (for males in the region of $1 \mathrm{~m}^{\circ} \mathrm{C}^{-1}$, and for females approximately $10 \mathrm{~m}^{\circ} \mathrm{C}^{-1}$ ) when only temperature at depth is considered. However, given the comparatively extreme dive depths reached by seals from Marion Island, and the seals' extreme lifestyle whereby they spend $>80 \%$ of their lives at sea, and $>65 \%$ at depths deeper than $100 \mathrm{~m}$ (McIntyre et al. 2010), the accumulated increases in dive depth associated with warmer water temperatures are likely to result in long-term increased physiological costs associated with diving. Also, individual differences in behaviour were accounted for in our models by specifying individual seals as random effects and calculating the variance thereby explained. This suggested substantial differences in behaviour among males (not females), resulting in some males increasing their dive depths substantially more with increases in temperature than the model coefficients suggest. The potential lifetime costs associated with such extreme diving is unknown at this stage, but circumstantial evidence such as the comparatively younger breeding ages (de Bruyn 2009), as well as deeper diving (McIntyre et al. 2010) of Marion Island elephant seals compared to other populations, suggest a potential influence worthy of further study. We have preliminarily labelled this a 'deeper diving-shorter life' hypothesis.

A further criticism from Boersch-Supan et al. (2012) regards our interpretation of the link between a timeat-depth index and temperature at depth. We reported that seals tended to spend less time during the bottom phases of dives when they were foraging in warmer water. We suggested that seals were spending less time at profitable foraging depths when employing dives with shorter bottom phases, and were therefore likely to be less successful foragers. 
No assessment of forage success was undertaken in our study due to a lack of available data on the body condition of tracked seals. Also, proxy measures such as measuring changes in vertical displacement when seals perform resting dives, as indicators of changes in lipid:muscle ratios (i.e. increased blubber results in increased buoyancy; Biuw et al. 2003, Mitani et al. 2010), were not considered feasible for our dataset (see McIntyre et al. 2011b for a discussion of this). Since the assessment of comparative duration of bottom phases as an indication of forage effort is common in tracking studies of diving marine animals (e.g. Schreer et al. 2001, Fowler et al. 2006, Bailleul et al. 2008, Zimmer et al. 2010, Staniland et al. 2011), we consider our analysis using a time-at-depth index a valid method. Our interpretation that increased time spent at depth indicates increased foraging success is somewhat speculative, but it seems the most logical one given the extreme habits of elephant seals, and the unlikely events of seals ignoring potential prey available at target depths. We agree that future investigations should take into account the body condition of tracked animals, in order to assess foraging success in relation to in situ environmental variables.

Boersch-Supan et al. (2012) conclude that one should additionally take prey distributions, and prey-specific foraging behaviour, into account to assess potential climate change effects on the behaviour of elephant seals. It would be particularly useful to include prey distribution data in such analyses, if such data were available. The species-specific diet of Marion Island southern elephant seals is virtually unknown (Bester et al. 2011), much less the actual distribution of such potential prey species within the Southern Ocean. The limited dataset described by Boersch-Supan et al. (2012) illustrates the lack of information available for biomass distribution (at depth) within the Southern Ocean. Future investigations using animal-borne camera systems and other new technologies such as multi-dimensional accelerometers (e.g. Davis et al. 2004, Watanabe et al. 2006, Naito et al. 2010), in combination with extensive prey field information such as that described by Boersch-Supan et al. (2012), will greatly enhance our understanding of oceanic predatorprey interactions. Prey-specific behaviour has not been demonstrated in southern elephant seals to our knowledge, although we agree that such behavioural differences would be important to inform better models of environmental effects on the behaviour of seals.

\section{Conclusions}

In the discussion of the results presented in McIntyre et al. (2011a), we clearly stated that the correlations we observed in dive behaviours of elephant seals and water temperature were likely due to an indirect link, whereby seals were tracking prey species which, in turn, were probably more directly influenced by water temperature. This led to the speculation that continued warming of the Southern Ocean would likely result in distributional shifts of prey species, thereby forcing elephant seals to also alter their foraging behaviour. In hindsight, the title of our manuscript ('Elephant seal dive behaviour is influenced by ocean temperature: implications for climate change impacts on an ocean predator') may have put undue emphasis on climate effects, rather than focussing on the strong relationship between elephant seal dive behaviour and temperatures at depth. We appreciate the discussion that our paper has generated, but suggest that Boersch-Supan et al.'s (2012) commentary is largely misplaced due to the limited overlap in study areas between the 2 studies, as well as their misinterpretation of our discussion around the potential longer-term influences of ocean warming. Nonetheless, their commentary has highlighted useful factors to be taken into account for future investigations.

Acknowledgements. We once again thank all the persons involved in the deployments of satellite tags on elephant seals at Marion Island over the past $9 \mathrm{yr}$. The Alfred Wegener Institute for Polar and Marine Research (Germany), the Department of Science and Technology through the National Research Foundation (South Africa) and the South African National Antarctic Programme provided financial and logistical support.

\section{LITERATURE CITED}

Bailleul F, Pinaud D, Hindell M, Charrassin JB, Guinet C (2008) Assessment of scale-dependent foraging behaviour in southern elephant seals incorporating the vertical dimension: a development of the First Passage Time method. J Anim Ecol 77:948-957

Bester MN, de Bruyn PJN, Oosthuizen WC, Tosh CA, and others (2011) The Marine Mammal Programme at the Prince Edward Islands: 38 years of research. Afr J Mar Sci 33:511-521

> Biuw M, McConnell BJ, Bradshaw CJA, Burton HR, Fedak M (2003) Blubber and buoyancy: monitoring the body condition of free-ranging seals using simple dive characteristics. J Exp Biol 206:3405-3423

Boersch-Supan PH, Boehme L, Read JF, Rogers AD, Brierley AS (2012) Elephant seal foraging dives track prey distribution, not temperature: Comment on McIntyre et al. (2011). Mar Ecol Prog Ser 461:293-298 
Campagna C, Piola AR, Rosa Marin M, Lewis M, Zajaczkovski U, Fernandez T (2007) Deep divers in shallow seas: southern elephant seals on the Patagonian shelf. Deep-Sea Res I 54:1792-1814

Davis RW, Hagey W, Horning M (2004) Monitoring the behavior and multi-dimensional movements of Weddell seals using an animal-borne video and data recorder. Mem Natl Inst Polar Res 58(Spec Issue):148-154

de Bruyn PJN (2009) Life history studies of the southern elephant seal population at Marion Island. PhD thesis, University of Pretoria

Fowler SL, Costa DP, Arnould JPY, Gales NJ, Kuhn CE (2006) Ontogeny of diving behaviour in the Australian sea lion: trials of adolescence in a late bloomer. J Anim Ecol 75:358-367

Le Boeuf BJ, Laws RM (1994) Elephant seals: population ecology, behavior, and physiology. University of California Press, Berkeley, CA

McIntyre T, de Bruyn PJN, Ansorge IJ, Bester MN, Bornemann H, Plötz J, Tosh CA (2010) A lifetime at depth: vertical distribution of southern elephant seals in the water column. Polar Biol 33:1037-1048

McIntyre T, Ansorge IJ, Bornemann H, Plötz J, Tosh CA, Bester MN (2011a) Elephant seal dive behaviour is influenced by ocean temperature: implications for climate change impacts on an ocean predator. Mar Ecol Prog Ser 441:257-272

McIntyre T, Bornemann H, Plötz J, Tosh CA, Bester MN (2011b) Water column use and forage strategies of female southern elephant seals from Marion Island. Mar

Editorial responsibility: Christine Paetzold,

Oldendorf/Luhe, Germany
Biol 158:2125-2139

McIntyre T, Bornemann H, Plötz J, Tosh CA, Bester MN (in press) Deep divers in even deeper seas: habitat use of male southern elephant seals from Marion Island. Antarct Sci

Mitani Y, Andrews RD, Sato K, Kato A, Naito Y, Costa DP (2010) Three-dimensional resting behaviour of northern elephant seals: drifting like a falling leaf. Biol Lett 6: 163-166

Naito Y, Bornemann H, Takahashi A, McIntyre T, Plötz J (2010) Fine-scale feeding behavior of Weddell seals revealed by a mandible accelerometer. Polar Sci 4:309-316

Schreer JF, Kovacs KM, O'Hara Hines RJ (2001) Comparative diving patterns of pinnipeds and seabirds. Ecol Monogr 71:137-162

Staniland IJ, Morton A, Robinson SL, Malone D, Forcada J (2011) Foraging behaviour in two Antarctic fur seal colonies with differing population recoveries. Mar Ecol Prog Ser 434:183-196

> Tosh CA, Bornemann H, Ramdohr S, Schröder M and others (2009) Adult male southern elephant seals from King George Island utilize the Weddell Sea. Antarct Sci 21: 113-121

Watanabe Y, Bornemann H, Liebsch N, Plötz J, Sato K, Naito Y, Miyazaki N (2006) Seal-mounted cameras detect invertebrate fauna on the underside of an Antarctic ice shelf. Mar Ecol Prog Ser 309:297-300

Zimmer I, Wilson RP, Beaulieu M, Ropert-Coudert Y, Kato A, Ancel A, Plötz J (2010) Dive efficiency versus depth in foraging emperor penguins. Aquat Biol 8:269-277

Submitted: June 13, 2012; Accepted: June 21, 2012 Proofs received from author(s): July 19, 2012 